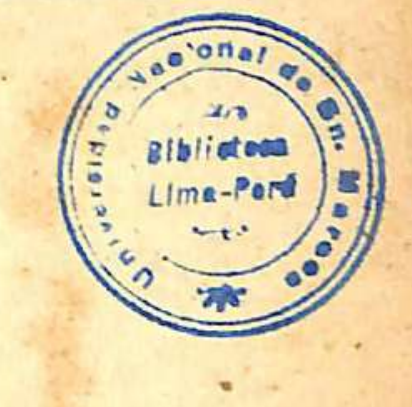

\title{
EL TESTIMONIO DE LAS EPOPEYAS HOMERICAS
}

L' Iliada et l'Odyssée sont l'expresion la plus nette et la plus franche de la civilization durant les deux premiers siecles que suivent immediatament la prise d'ilion. - Dugas Montbel.

\section{LOS ANTIGUOS POEMAS GRIEGOS}

Casi todo lo que sabemos de la proto-historia de Grecia nos ha sido revelado por la poesía los Gedas 6 cantores, Como los trovadores de gesta en la Edad Media hicieronedẹ las tradiciones heróicas, que corrían en boca del pueblo, objeto de sus cantos. Se sabe que el acontecimiento político, conservado por el relato tradicional, perdura y se hace inviolable, gracias al auxilio que le presta la poesía y la religión. Los cantos de estos aedas fueron innumerables, y si se hubieran conservado, se conocería con detalles la historia primitiva de casi todos los estados de Grecia; desgraciadamente sólo han subsistido aquellos que la labor de los compiladores reunió, por referirse a algún acontecimiento notable que fué el hecho central del relato, o que recibió la unidad, gracias a la labor sistematizadora de la teogonía. Así, tres son únicamente los poemas conocidos: la lliada y la Odisea que han debido ser compuestos entre el siglo IX y el final del VIII y los Trabajos y los días de Hesíodo. Tales poemas nos ofrecen cuadros de la vida griega en sus aspectos más interesantes: las guerras con sus peripecias; la navegación con sus aventuras y la agricultura con sus encantos. "Trilogía admirable que ha idealizado las pasiones, las costumbres, las ideas de una humanidad singularmente enérgica, prestándole tal belleza, que toda la vida ulterior del pueblo griego, se halla impregnada de sus encansos". 


\section{LOS HEROES EN LAS LEYENDAS}

Los relatos legendarios que se convirtieron en poemas fueron los de indole esencialmente política. La rica imaginación helénica halló, en estos temas, el mejor material para estimular su fantasía. La abundancia de estas tradiciones heróicas fué también la causa de que se generalizaran los cantos poemáticos y que cada ciudad, cada tribu y hasta cada familia tuvieran su héroe y su cantar de alabanzas, y. ficticios o verdaderos, semejantes relatos, constituian los títulos de su nobleza y de su poder. "Cada uno de los grupos humanos que habían inventado el relato, había puesto en él lo más caro de sus recuerdos y afectos, su carácter nacional, la imagen de su pasado, y, en el héroe, el símbolo de su ideal.

$U_{n}$ relato épico se contrae generalmente a la narración de sucesos que se producen teniendo por figura central a uno o muchos personajes, a veces a una familia entera. Estos personajes representativos son los héroes; hombres divinizados, hijos de una mortal y un Dios y dotados, por lo mismo, de una dobles naturaleza, como hombres sujetos a las miserias físicas y morales, como descendientes de un Dios, dotados de cualidades superiores: fuerza, destreza, inteligencia, belleza y prudencia.

Estas cualidades son, por lo común, las aptitudes de la raza griega; poseidas en gradg máraimo, conviertep al hombre en un tipo de perfección. Y esto explica dorof que han jügadên el desenvolvimien-

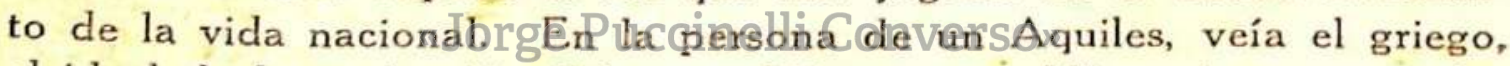
el ideal de la perfección física; en Néstor o en Ulises, la recta razón, la delicadeza espiritual, el sentido práctico de los negocios humanos, la astucia inteligente, la prudencia y discreción moral.

\section{LA ILIADA}

El más copioso e importante poema heróico de este ciclo es la Iliada. Su episodio central es la lucha de los griegos contra Troya, ciudad pelásgica del Asia Menor. La causa de la guerra es el rapto de Helena por Paris hijo del rey troyanodo Príamo. Menelao Rey de Esparta, esposo de la raptada, pide apoyo a su hermano Agamenón para vengar la ofensa. Agamenón rey de Micenas y Argos, llama a los principibs griegos a la defensa del honor nacional herido en la persona de Menelao, y a su proclama acuden los príncipes de varios reinos y organizan la expedición contra los txoyanos. En el poema los griegos son llamados aqueos o eolios y tiryos, y los troyanos nombrados descen(f) 
de razas, lucha de intereses entre gentes de una misma nación, desvinculadas por una remota escisión en el espacio y en el tiempo. "Que la colonización eolia, dice Curtius, haya tenido el privilegio de dar origen a estos cantos heróicos, es un hecho que explica las circunstancias particulares en que se verificó. Era esta una ocasión única para conquistar la gloria de los héroes; el acto se realizaba por esa raza aquea que la inspiración impulsaba a asociar la poesía al heroismo".

Los aqueos y los dardanios son pueblos de la misma raza y por eso toda la guerra de Troya, cantada por Homero, no tiene otro carácter que el de una querella entre vecinos, como podía surgir, y surgía con frecuenoia, entre las tribus griegas, a propósito de un rapto de jóvenes o de un robo de ganados. Por esta misma razón no hay un rasgo en la (1) dientes de esos viejos dardanios que tienen por ancestrales a los propios dioses del Olimpo griego. La guerra de Troya fué, más que lucha leyenda de Troya que no haya debido producirse en otras circunstancias análogas. Estos rasgos no garantizan, pues, en modo alguno, el valor histórico del relato; pero hay otros detalles particulares a la leyenda de la guerra de Troya, en los que se descubren las huellas de una antigua tradición, que sólo conviene al tiempo y que sólo se explica por la coincidencia de la colonización eolio-aquea" (1).

Por fin termina la guerra, con la toma de Troya, gracias a los planes astutos de Ulises. Los vencedores se reparten un cuantioso botín y regresan a sus patrias. A este episodio fundamental se unen relatos desconectados de la acción primaria; episodios de la vida y peripecias de los héroes; que hacen perder al poema su unidad y que revelan la interpolación ó agxupación de variadas leyendas dentro de un tema militar (2). Blblioteca de Letras

Los autores deoste foniglomerado poético, los rápsodas, no pudieron disfrazar este zurcido de leyendas, pero en cambio, formando el poema con mal disfrazada unidad, conservaron hechos históricos memorables y una fuente de averiguación del carácter de estos tiempos, heroicos de esa vida militar y luchadora de la proto-historia griega. Así la Iliada al mismo tiempo que es el poema de la guerra, es la más alta fưente histórica de la época.

(1) Curtuis. Historia de Grecia.

(2) Agrégase a estas particularidades las numerosas reminiscencias de otros combates que se incluyen en la leyenda de Troya sin tener relación con la ciudad de Príamo ni con el rapto de Helena, como las lejanas expediciones de Aquiles por mar y por tierra, la toma de Tenedos, de Lesbos, de Lyrnesos y de Thebas; la llegada, desaparición y regreso de los sitiadores, rasgos todos que indican claramente un largo período de hostilidades, una conquista territorial proseguida, paso a paso, una toma de posesión. "La guerra de Troya es pues, dice Curtius, en definitiva, tanto a juicio nuestro cuando al de Tucydides, la primicra empresa realizada en común por las más notables tribus helénicas, sólo que nosotros tenemos derecho a colocar esta guerra, que tomada aparte es incomprensible, en un más vasto tejico de sucesos, y a sacarla de la edad poética a donde la transportó la musa homérica, para colocarla en la época real de la lucha". 


\section{LA GUERRA A TRAVES DE LA ILIADA}

La acción de Paris es un rasgo significativo de las costumbres. Nos muestra el rapto de mujeres, realizado no por piratas, sino por príncipes, como una práctica generalizada, que no deshonraba ni a la familia ni al pueblo. En el poema, la violencia toma caracteres de gravedad por la perfidia que la acompaña, pues Paris ha burlado la hospitalidad, y es principalmente la ingratitud a sus protectores lo que coloca al troyano fuera de la ley. El respeto al extranjero acogido en el hogar es un deber sagrado para los aqueos y ese respeto es ya el reconocimiento del derecho de gentes que nacía. Véase sino esas declaraciones llenas de piadosa unción con que se declara este deber sagrado común a los hombres y a los dioses:

No es lícito

Tratar con menosprecio a ningún huésped

Porque vienen

Todos los extranjeros y mendigos de Jove.

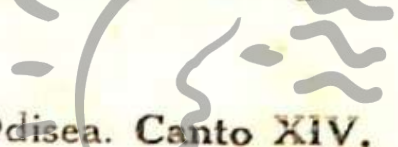

\section{Odisea. Canto XIV.}

De igual modo cuando Ulises entra al palacio de Alcinoo solicitando hospedaje, los magnates del reyno reclaman del rey honor y mercedes para el peregrino:Biblioteca de Letras
Alcinoo, "Jorge.Puccinelli Converso"
Questábien, ni es decoroso
Que ese extranjero esté en el suelo duro
Sentado en la ceniza. Aquí nos tienes
Esperando a que hables. ${ }_{1}$ Ea! en silla
De clavazón de plata, hazle sentarse;
Manda que los heraldos nos ofrezcan
Dulce vino, y hagamos libaciones
A Júpiter Tonante, que acompaña
Al suplicante venerable, y luego
Sírvale la honorable despensera
Los manjares que tiene a su cuidado.

\section{Odisea. Canto VII.}

La destrucción de Troya es un acto de reparación a la Moral y a la Justicia. Hecho digno de consideración es también el sentimiento de confraternidad o solidaridad entre los príncipes. La ofensa a Menelao se considera como una injuria a la colectividad y determina, por lo mis- 
mo en los príncipes, el reconocimiento de un jefe único para la lucha. Tal es la solemne declaración que hace Ulises ante los príncipes aqueos.

No es bueno

El gobierno de muchos: uno sólo

El caudillo supremo y soberano

De todos sea; aquel a quien el hijo

De Saturno ha dado el cetro

$\mathrm{Y}$ regia autoridad para que mande.

\section{Iliada. Canto II.}

En plena guerra vuelven a revelarse esos rasgos de un naciente derecho internacional en la conciliación entre los dos partidos, después de juramentos solemnes, por cuyo medio se intenta poner término a la lucha. Es verdad que muchas veces estos juramentos son violados; pero esto no ocurre sin la protesta de los que no están cegados por la pasión. Verdad que ese derecho de gentes no era entonces ni muy preciso ni muy amplio. Así los troyanos convencidos ya de su derrota, preveen la ruina de su ciudad que será incendiada y saqueada, sus habitantes pasados a cuchillo y sus mujeres distribuídas entre sus vencedores para servir de esclavas o de concubinas; lo que se verificó efectivamente, según los relatos de los poemas complementarios a la Iliada; los defensores han de ser, también, o muertos o vendidos como esclavos a gracia o voluntad del bencedor; Doscadáveres de-los troyanos han de quedar insepultos. «JAśg lopdeclara tristemente Héctor en la tierna despedida que dirige a su esposa antes de marchar al combate:

........Bien conozco

Y el corazón y el alma lo presienten,

Que ha de llegar el día en que asolado

Será la fuerte llión, y en que prerezca.

\section{Iliada. Canto VI.}

En fin, si los aqueos combaten por el derecho, sus principales jefes no disimulan que, a este noble propósito se une el deseo del botín, perseguido con avidez. Sin embargo, es una gloria y un honor para esa raza, la espontaneidad de sus sentimientos generosos, que adelantaban los progresos siempre lentos del derecho y las costumbres morales. La entrevista de Príamo y Aquiles equivale a una revelación casi divina de los sentimientos de humanidad, en medio de un estado de cosas que conservaba supervivencias de barbarie. Una viva emoción provocan los ruegos y súplicas del viejo Príamo abrazando las rodillas de Aquiles e im- 
plorando piedad para honrar a Héctor, vencido y muerto, y recordando al vencedor las veleidades de la fortuna.

Como atónitos quedan y admirados

los que a la casa ven, de un poderoso

derrepente llegar al suplicante,

que un hombre ha muerto en su país nativo

y el castigo temiendo amparo busca

en extraña región; tan admirado

quedó Aquiles al ver dentro su tienda

al venerable Príamo; y a los otros

Mirmidones también, y se miraban

los unos a los otros. El primero

habló al anciano Rey, y en dolorido

acento dijo al campeón de Acaya:

"De tu padre te acuerdas ilustre Aquiles,

" que en rugosa vejez ya de lanvida

"al término se acerca, y tan anciano

"es como yó. ¿Quién sabe si a estas horas

"los Reyes comarcanos poderosos

"le oprimen con sus armas, sin que tenga

"quien le socorra y de la muerte libre?

"Pero tu padre en fin, oyendo ahora

"que tú vivesi espoerat cada día Ietras

"verte llegar de Trgya yo se consuela;

"y yo el más desdichado de los hombres,

"habiéndome los Dioses concedido

"tantos hijos valientes que de Troya

"eran los defensores, decir puedo

"que ninguno me queda. Cuando vino

"la hueste de los Griegos a esta playa

"cincuenta hijos tenía (diez y nueve

"de Hécuba me nacieron, y los otros

"de diversas mujeres), y la vida

"a casi todos el furioso Marte

"habiendo ya quitado, me quedaba

"uno solo que a Troya defendiese:

"y tú, no ha mucho, le matacte, jay triste!

"mientras él por su patria combatía.

"De Héctor hablo, y él es quien me ha traído

"a las naves aqueas. Que me entregues

"su cadáver te pido, y un rescate

"traigo de gran valor. Respeta, Aquiles,

"a los eternos dioses, y te duele

"de este infeliz anciano a la memoria 
"recordando la imagen de tu padre.

"Yo soy más infeliz; pues obligado

"a sellar con mis labios ya me veo

"la mano del varón que dió la muerte

"a tantos hijos míos; desventura

"a que jamás llegaron las desgracias

"de otro ningún mortal". Así decía

el afligido Rey; y de su padre

acordándose Aquiles, gran deseo

le vino de llorar y con la mano

a Príamo intentó de sus rodillas

alejar blandamente; pero el triste anciano de sus pies no se apartaba, y en lágrimas los dos se deshacían.

A Héctor lloraba Príamo; y Aquiles por su padre, y a veces a Patroclo $\mathrm{y}$ en contorno la tienda resonaba de los dos con los llantos y gemidos. Pero después que de llorar el héroe se hubo cansado y satisfecha el alma quedó del tierno lloro, de la silla se levantó cortés.

\section{Iliada. Canto XXIV \\ Biblio LOS COMBATES}

La guerra contra Troya se concreta principalmente al asedio de la ciudad. El sitio, sin embargo, se contrae sólo a un indefinido bloqueo, en el que no se emplean ni las máquinas de guerra ni los asaltos, la técnica militar se revela incipiente. Los ejércitos ofrecen, eso sí, una cuidadosa organización y están mandados por los jefes que forman gerarquía. En el poema el narrador se cuida principalmente de exaltar el coraje e inspirar las acciones de los héroes en motivos de orden moral: el patriotismo, el honor, el deseo de sobresalir y de vengar ofensas recibidas. Nada es más elocuente en este sentido que el discurso de Helena a Héctor recordando la cobardía de Paris:

iAy! hiciera

el cielo al nacer yo, que un remolino

de borrascoso viento a las montañas

me hubiese arrebatado, o a las olas

del estruendoso piélago me hubiera

al término llegara, antes que hubiesen

arrojado y en ellas de mi vida 
tales estragos de mi error nacido!

Pero ya que en su cólora los dioses

que estos males llegaran decretaron,

ser esposa debía de un guerrero

más vaelroso, y que sensible fuera

al desprecio y al odio de los hombres;

mas éste ni valor tiene en el pecho,

ni lo tendrá jamás, y vendrá día

en que de su vileza coja el fruto.

Cuando la debilidad o el miedo obligan a los soldados a ceder, la voz de sus jefes, recordándoles el honor, censurándoles su cobardia, se hace oir amenazadora o persuasiva. La razón y el sentimiento son allí estimulantes del valor y del arrojo. "El honor es entre ellos, el motivo fundamental de la acción. Ninguno se resigna a ser tildado de cobarde; y el amor a la gloria es el ideal común; en los jefes este amor se convierte en verdadera pasión. Al honor se junta el patriotismo". Quieren honrar a sus patrias y mantener el crédito de sus linajes. Entre los troyanos el patriotismo es a la vez sentimiento de honor y de defensa de la familia, de los dioses y el hogar. I a proclama de Héctor es revelación de estas ideas. "El mejor de los presagios, dice, es pelear por la ciudad de nuestros padres". El poeta muestra a veces el contraste entre el orden y la disciplina de los aqueos y la confusión en el ataque, por parte de los troyanos; quiere así mostrar las condiciones de superioridad de un buen ejército, en el que la firmeza, la ordenación, el rigor disciplinario y la gallardía, son sus cualidades fundanentales; las que se encuentra también en todas las manifestadioniesedèlCespiritusgriego.

\section{EL CONSEJO Y LAS A.SAMBLEAS}

Cuando el ejército no combate se convierte en pueblo. Pónense entonces en juego sus instituciones. Muéstrase una reyecía aristocrática, con un rey supremo, jefe de los ejército y árbitro de los príncipes: Agamenón; un Consejo que delibera bajo la presidencia del Rey, sobre los asuntos importantes, y por fin la gran Asamblea, o el pueblo, representado por la totalidad del ejército, a quien el rey comunica las decisiones de la Asamblea, y que la masa aclama con sus clamores y el ruido de sus escudos.

Tal forma de Gobierno concede importancia fundamental a la palabra: deliberaciones del Consejo, entrevistas de los jefes y los embajadores, exortaciones al ejército, arengas pronunciadas en la Asamblea. Tal se muestra en su origen esa democracia de la polis griega, que, si bien es sencilla en estas primeras manifestaciones, ha de revelar toda su potencia 
y su eficacia en los períodos en que no sea la guerra la que domine, sino la paz.

La Iliada, se ha dicho, es el poema de la guerra y el himno de alabanza a los vencedores; mas si es verdad que la ponderación de los héroes aqueos constituye el nexo de la epopeya, no se olvida por eso, a los vencidos, y, gloria muy grande es para el genio griego, esta elevada generosidad e hidalguía, que muestra a favor del humillado. Algunas escenas son a este respecto, significativas. El más brillante de los guerreros troyanos, Héctor, vuelto por unos instantes a la ciudad, antes de su lucha con Aquiles encuentra a su bella esposa Andrómaca acompañada de la nodriza que lleva en brazos a su único hijo: Astiacté; frases de amor y ternura se cruzan entre Héctor y los seres queridos, cuando se resuelve regresar a la palestra; Andrómaca bañada en lágrimas le pide que viva para ella y para su hijo. Despréndese Héctor de sus brazos, recordándoles su deber sagrado, y rogando a los dioses, velen por la madre, y hagan de su hijo un príncipe más feliz. Nada más emocionante que el cuadro de las angustias de Príamo, Hécuba y Andrómaca ante el combate y la muerte de Héctor que presencian desde los muros de Troya:

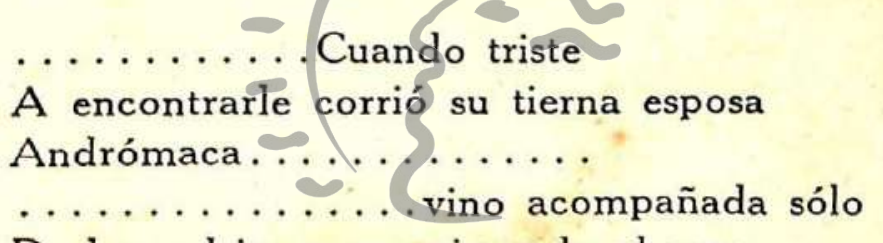

De la nodriza que arrimando al seno

A Astiacté llevaba. Era este nina.S

De Héstor única pirolèli C parecíaso»

Un lucero, y su padre le pusiera

El nombre de Escamandrio........

Cuando el héroe

Al niño vió se sonrió en silencio;

Y Andrómaca, acercándose afligida

lágrimas derramaba. $\mathrm{Y}$ al esposo

asiendo de la mano, y por su nombre

llamándole decía acongojada:

“iInfeliz!. Tu valor ha de perderte;

"ni tienes compasión del tierno infante,

"ni de esta desgraciada, que muy pronto

"en viudez quedará, porque los griegos

“cargando todos sobre tí, la vida

"fieros te quitaran. Más me valiera

"descender a la tumba, que privada

"de tí quedar; que si a morir llegases,

"ya no habrá para mí, ningún consuelo, "sino llanto y dolor"........... 
Respondió el héroe a su afligida esposa:

"Nada de cuanto dices se me oculta;

“pero temo también lo que dirán

“contra mí los Troyanos y Troyanas.

"si cual cobarde de la lid huyera.

"Ni lo permite mi valor, que siempre

“intrépido he sabido presentarme

"en la liza, y al frente de los Teucros

äpelear animoso por la gloria

"de mi padre y la mía. Bien conozco

“y el corazón y el alma lo presienten,

"que ha de llegar el dia en que asolado

"será el fuerte Ilión, y en que perezcan

"Príamo y su nación tan poderosa.

"Pero no tanto la común rüina

"que a los demás troyanos amenaza,

"ni de Hécuba la suerte y de mi padre

“el Rey Príamo siento y/mis hermanos,

"que muchos y valientes por la diesira

"de nuestros enernigos en el polvo

“derribados serán como la tuya;

"que alguno de los Príncipes aqueos,

"dejándote la vida, por esclava

"a Argoß tebllegolrá brañada em lloros

"Y allí, de una extranjera desdeñosa

"obediente a la voz, a pesar tuyorso"

"y a la necesidad cediendo dura,

"la tela tejerás e irás por agua

"a la fuente Meseida o Hiperea.

"Y cuando vayas, los Argivos todos

"que te vean pasar triste y llorosa

"el uno al otro se dirán alegres:

"Esa es la viuda de Héctor, el famoso

“campeón de todos los Troyanos

“era el más fuerte cuando en torno al muro

“de Ilión con los griegos peleaban.

“Así alguno dirá, y al escucharle

"nuevo dolor afligirá tu pecho;

"y mucho entonces sentirás la falta

"de tú Héctor, el sólo que podría

"de esclavitud sacarte si viviese.

"La tierra amontonada mi cadáver

"antes oculte, que llevarte vea

"por esclava y escuche tus gemidos". 
Luego de pronosticarle la ruina de Troya y la triste suerte de los vencidos, sigue el poeta:

Así decía y alargó la mano para tomar en brazos al infante; pero asustado el niño, sobre el pecho de la nodriza se arrojó gritando: porque al ver la armadura refulgente y la crin de caballo que terrible sobre la alta cimera tremolaba se llenó de pavor. Su tierno padre y su madre amcrosa se reían y el héroe se quitó de la cabeza el casco reluciente, y en el suelo poniéndole, en sus brazos al infante tomó y acarició. $\mathrm{Y}$ al dulce beso imprimiendo en su cándida mejilla, esta plegaria al soberano Jove dirigió y a los otros inmortales: “Padre Jove, y vosotras bienhadadas "Deidades del Olimpol Concededme "que mi hijo llegue a ser tan esforzado "como yo, y a los Teucros aventaje "en fuerzas y valor, y que algún día "sobre Ihỏn impere pederoso:etras "y que af verle polvewn delias batallas, "trayendo por despojo en sangre tinto "el arnés de un guerrero a quien la vida

"él mismo haya quitado, diga alguno:

"Este es más valeroso que su padre; "y Andrómarca se alegre al escucharlo".

\section{Iliada. Canto XXVI.}

El término del poema que describe los funerales de Héctor, muestra tal elevación moral y delicadeza de sentimientos, que si bien su objetivo ha sido la exaltación de las virtudes guerreras, la esencia de sus cantos es la ponderación de las más elevadas virtudes morales y de los sentimientos más humanos. El alma griega se revela en él, mostrando las altas cualidades de su cultura:

......... Cuando al orbe

iluminó la aurora refulgente por la décima vez, de su Palacio sacaron de Héctor el cadáver tristes; 
y colocando sobre la alta pira, por todas partes le pusieron fuego.

Apenas con su luz e! alba pura anunciaba ya el día, el pueblo todo en derredor de la anchurosa pira que de Héctor el cadáver abrazara se reunía. Cuando ya estuvieron en numerosa turba congregados, con oloroso vino aquella parte de la pira que el fuego consumiera apagaron, y luego los amigos y los hermanos de Héctor recogieron los blancos huesos, sollozando tristes y en abundantes lágrimas regando las cenizas del héroe. Recogidos los albos huesos ya, los escondieron en urna breve de oro que cubría finísimo cendal, y dentro el hoyo la enterraron, con grandes y apiñadas piedras tapando la abertura, y luego la tierra amontonaron; y tenian por todas partes atalayas puestas, no fuese que entre tanto las Aquivos acometieran. Cuando ya la tumba hubieron erigido, a sus hogares volvieron todos; $y$ Cal venir la noche de nueyorreunidesienelai cercarerson del alcázar de Príamo, el convite funeral celebraron. Las exequias tales fueron que hicieron los Troyanos al adalid de sus legiones, Héctor.

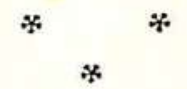

\section{EL POEMA DE LA PAZ: LA ODISEA}

La segunda de las epopeyas griegas la Odisea o Ulisea, es complemento de la Iliada, y nos muestra la otra faz de la vida griega: el trabajo, el comercio, las costumbres y usos de la sociedad y del hogar doméstico; con razón ha sido llamado el poema de la paz. Su argumento lo forman las peripecias de Ulises en el largo y peligroso viaje 
que emprendió para regresar a su patria, Itaca, después de la caída de Troya. A diferencia de la lliada de composición tan heterogénea y ampulosa, la Odisea ostenta una marcada unidad, una gran harmonía y enlace entre sus partes y una fisonomía de sencillez y de ingenuidad que seduce y encanta. El autor del poema ha debido aprovechar de las leyendas que los isleños del mar interior conservaban de sus aventuras y piraterías para enlazarlos como episodios de su héroe Ulises, y hacer del relato de las hazañas de éste, la más movida, interesante y fantástica de las narraciones. Con razón Mr. Berard ha sostenido que la Odisea "parece ser una trascripción poemática de los informes geográficos, de una gran precisión, reunidos por un pueblo de marinos para servir de guía a los navegantes". En el poema, en efecto, se ofrece, como teatro de las acciones del héroe un vasto panorama: es casi toda la comarca del Mediterráneo, notándose la precisión con que se describen las costas del Norte de Africa y del Mediterráneo Occidental, así como los parajes de Sicilia; y, no obstante de que en la época en que fué compuesto el poema, esas tierras no eran conocidas ni las visitaban los marinos; se les suponía pobladas de dioses gigantes, monsturos, o pueblos de extraños habitantes, como los lotófagos, los lestrigones y los cíclopes; un/indicio más de que las leyendas que forman su trama habían sido creadas en época remota, por gentes que conocían esos parajes antes de que la leyenda la envolviese entre su red maravillosa.

Ya lo dice así el poeta al iniciar sus cantos:

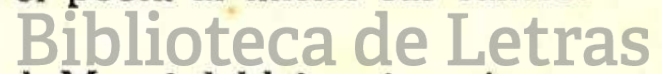

¡Dime oh Musa! del héroe ingenioso

Que después de arrasar la sacra Troya

Anduvo tanto tiempo peregrino

Viendo muchas ciudades y costumbres

Conociendo...........

\section{Odisea. Canto I.}

La exactitud en las descripciones geográficas y ese noticiero amplio que ofrece el poema ha llamado la atención de los antiguos, como Platón, Longino, y sobre todo Estrabón que llama a Homero el Príncipe de la Geografía.

$\mathrm{Y}$, así, en el poema, Ulises se muestra como el modelo del buen marino y con las cualidades a éste inherentes; diestro en la faena de mar, hábil armador, piloto amaestrado y náutico admirable, inteligente en el conocimiento de su derrotero y seguro en guiarse por las seña- 
les de la tierra. No navega sino durante el día, temiendo perder su ruta en las tinieblas, y, cuando llegar tarde, encalla en la playa (1).

\section{Odisea. Canto XII.}

Prudente hasta el exceso; cuando toma los caracteres de la indecisión, su valor e intrepidez, revelan la potencia de su carácter y la firmeza en sus más audaces resoluciones. Los peligros no lo abaten: contra las tempestades halla el refugio para su barco, contra los enemigos, fuerzas superiores. En los países enemigos, observa, en sus contrarios, usos y costumbres; se percata de sus debilidades y defecto;s en ocasiones sus aventuras desgraciadas nos muestran la angustiosa vida del marino, juguete de las olas, atormentado del hambre y de la sed, náufrago en costas inhospitalarias. Enseña por lo demás lo que vale la disciplina de los tripulantes, el valor de la serenidad y de la presencia de ánimo en el marino, y, más aún, en el jefe, dotado de las condiciones de severidad y competencia en el comando para conducir sus empresas al éxito. Así analizado el poema es verdaderamente la epopeya de un pueblo de marinos.

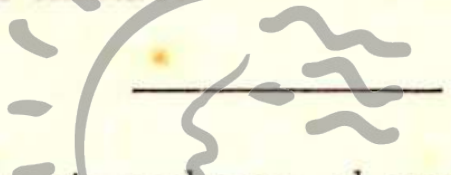

Hay que observar, sip embargo, el otro aspecto del poema; el que ofrece de la vida doméstica y de las costumbres.

En el palacio de Itaca, Penépole, la esposa del héroe, y su hijo Telémaco, aguardan año tras año, la vuelta del peregrino. Los príncipes

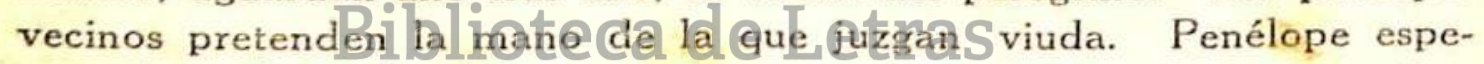
ranzada en la vuelfa debamante pspason rehusa casarse de nuevo, mientras una prueba fehaciente no le convenza de la muerte de Ulises. Ante esta negativa, Ins pretendientes se instalan en el palacio real tomando posesión de lo, bienes del ausente y disipándolos insolentemente. El joven Telémaco, sin autoridad ni fuerza para arrojarlos, parte en bus-

$$
\begin{aligned}
& \text { Anigos míos, les decía, no son nuevos } \\
& \text { Para noso ros los peligros. Este } \\
& \text { No es mayor en verdad, que el que corrimos } \\
& \text { C:1ando con fuerza incontrastable, el Cíclope } \\
& \text { Nos encerró en su cueva, y con mi audacia } \\
& \text { Y mi astucia os salvé, según entiendo } \\
& \text { Que no habréis olvidado. Obedecedme } \\
& \text { Ahora puntualmente, en cuanto os mande. } \\
& \text { Sentados en el barco herid vosotros } \\
& \text { Con los remos del mar las hondas olas; } \\
& \text { Quizá Jove permita que escapemos } \\
& \text { Por esta vez siquiera de la muerte; } \\
& \text { Tú, piloto, tendrás graba mis órdenes } \\
& \text { En tu mente; pues vas al gobernalle } \\
& \text { Bien separado el cóncavo navío } \\
& \text { De ese humo y de esas olas; mira siempre } \\
& \text { Al escollo, no vaya desviada } \\
& \text { La nave a destrozarnos mal tu grado. }
\end{aligned}
$$


ca de su padre, el que, al fin, regresa sólo y sin recursos para vencer a los audaces. Toda la segunda parte del poema se concreta a narrar la reconquista del hogar. Ulises, disfrazado de mendigo, penetra al palacio, observa la vida licenciosa y disipada de los pretendientes; por fin venciéndolos, recupera el trono. El relato es rico en escenas emocionantes y en descripciones precisas y curiosas, que nos instruyen plenamente a cerca de la vida íntima de los griegos de esa época.

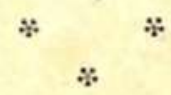

\section{ENSEÑANZA QUE DAN LAS EPOPEYAS}

Los epopeyas homéricas son el fiel reflejo de esos tiempos heróicos y muestran los dos aspectos de la vida griega: la guerra y la paz, las estructuras políticas y las costumbres: las atribuciones de los reyes y los deberes de los súbditos; la fisonomía moral e intelectual de la época.

La forma de Gobierno es la monarquía de clan o aldea, y cuyo dominio es de poca extensión. La isla de Itaca comprendía doce reynos. Micenas y Argos, distantes algunos kilómetros, constituían dos reynos diferentes $y_{-}$colocados entre los más importantes. Salamina era otro. El Atica segin una tradición constante, formaba muchos reynos. Y así sucesivamentege Puccinelli Converso»

Todos estos reyes no eran en su origen más que unos modestísimos jefes de clan. Ulises era el rey de los reyes de la isla de Itaca, dice Homero.

“Agamenón rey de Micenas, agrupa en torno suyo, cierto que para realizar una expedición temporal, a los jefes de Grecia. Evidentemente, la idea de una expedición panhelénica dirigida contra Troya es en absoluto legendaria y de fecha relativamente reciente. Pero ha nacido de un hecho cierto, el gran poder relativo de los soberanos de Micenas, cuyas fortalezas imponentes habían herido la imaginación de los contemporáneos, y nosotros podemos entrever aún gracias a recientes excavaciones, entre el lujo bárbaro de su oro y de sus palacios. Poco a poco los jefes de los clanes más débiles, los reyes inferiores, por decirlo así, tendían a agruparse al rededor de los más fuertes, y pasaban a ser sus vasallos, compañeros de los reyes poderosos, cuya corte habitual constituían: son ya una sencilla aristocracia".

"Los reyes son hijos de Zeus, es decir, que su origen se confunde con el del clan, que es anterior a toda historia, y que su dignidad he- 
reditaria, misteriosa, parece divina como todos los fenómenos, asombrosos por su magnificencia".

Los que entre ellos son más poderosos viven con fausto mezclado de sencillez. Sus palacios donde se amontonan las riquezas y donde viven gran número de criados, se rigen por cierto ceremonial (1). Una reyna homérica llámese Helena o Penćpole, no desciende jamás del piso superior, donde viven las mujeres, sin llevar consigo el cortejo formado por dos servidoras. Sucédense con gran frecuencia, los banquetes y las fiestas musicales y poéticas: los reyes beben "como dioses" y esta existencia constituye para el pueblo el ideal de la vida feliz. Pero esta monarquía patriarcal no concce aún el uso de las tropas de mercenarios armados que más tarde guardarán la persona de los tiranos: el rey no siente la necesidad de defenderse contra sus súbditos, que le rodean con un respeto casi religioso: bastan sus criados ordinarios a preservar el palacio contra cualquier sorpresa de piratas o de ladrones; en caso de guerra sus hombres libres forman su ejército. El rey vigila los trabajos de sus campos y sabe él mismo trabajar con sus manos. Ulises construye su lecho y su casa; sabe hacer una balsa y guiar un barco.

El mismo exclama entre los Feacios con un énfasis que delata el orgulio del que se cree con uña habilidad nuanual incomparable:

Pronto a probarme, porque soy perito

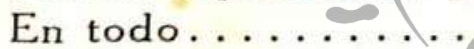

(1) He aquí la descripción del palacio de Alcinoo y un extricto ceremonial: $\mathrm{Y}$ antes de ientrân por ehumbral de bronce

Se paró, mil ideas revolviendo.

Como el britloodelpSpl yide la Lunaverso»

Así era el esplendor de aquelia casa.

Desde el umbral al fondo dos paredes

De bronce se extendian, con su friso

De azulado metal. Dos puertas de oro

Cerraban la morada inquebrantable

Por dentro; y del umbral de hermoso bronce

Dos argenteos postes arrancaban,

Sosteniendo el dintel de plata pura,

Y la aldaba era de oro. A entrambos lados

Estaban unos perros de oro y plata

Obra del dios Vulcano, que les puso

De muerte y de vejez para custodia

Visceras sabias, y los hizo inmunes

De la mansóin de Alcinoo magnćnims.

Desde el umbral al fondo de In cara

Había aquí y allá preciosas silá;

Adosadas al muro, con tapices,

Finísima labor de las mujeres,

Cubiertas, en las cuales a sentarse

Solian los Feacios más ilustres

A comer y beber, pues sus festines

Eran sin fin, sobre unos pedestales

De preciosa labor, mancebos de oro

Sostenían antorchas encendidas

para alumbrar de nohe los banquetes.

Ulises entre tanto se acercaba... 
Lo que prueba además con la construcción del barco en la isla de Calipso:

......... Empezó el héroe

A cortar troncos secos; y en su obra

Avanzaba veloz, porque en espacio

Breve derribó veinte, y con el hacha

Los debastó, encuadrólos hábilmente.

Y rectos los dejó. Calipso, en tanto

Le trajo unos barrenos con que todas

Las piezas taladró; juntólas luego,

$\mathrm{Y}$ con sendas clavijas y con muescas

Las apretó. Largura semejante

A la que hábil maestro da a la quilla

De un navío de carga, grande y largo,

Ulises dió a su balsa. El combés hizo

Con vigas y tablones sobrepuestos.

Construyó un alto mástil y la antena

Y el gobernalle de la balsa guía,

$\mathrm{Y}$, en fin, para reparo de las olas,

Cercola toda en torno de un tejido

De mimbre, y la lastró con muchos leños

Entretanto la diosa lienzos trajo

Para las velas, que el mañoso Ulises

Dispusóriontoy bies: até a labalsas

Las cuerdas y maromas yi bolinas
$\mathrm{Y}$ con unos parales poco a poco

Arrójola, por fin, al mar divino".

Levantó suave viento. Izó la vela

Con él alegre, Ulises, y sentado

Al gobernalle, diestro dirigía

La balsa, y nunca al sueño delicioso

Cerró sus ojos, mientras vió las Pléyades

$\mathrm{Y}$ el Boyero tardío en ocultarse,

O la llamada el Carro, Osa luciente,

Que, única en bañarse en el Océano

Gira, acechando a Orión, siempre en un puesto.

A su lado se ejercitan los hijos del rey. Su mujer dirige el trabajo de sus sirvientes y borda con sus propias manos telas preciosas. Sus hijas van al río o a la fuente a lavar las ropas de la casa real. 
De esas domésticas escenas que recuerdan las dulces pastorales de Teócrito, y en las cuales se inspiró el genio de Virgilio para componer sus églogas inimitables, ninguna más encantadora que la que presenta la sencilla faena de Nusicaa, y que no me resisto al deseo de trascribirla:

Le dijo la princesa, ¿no podrías

Ordenar que me den un alto carro

De ruedas muy veloces, en que pueda

ir al río a lavar las bellas ropas

Que he ensuciado y tengo separadas?

$\mathrm{Ni}$ cosa alguna. Vete; los criados

El alto carro te darán, provisto

De ágiles ruedas y profundo cofre".

Dijo y mandó a sus siervos, que obedientes

Su3 órdenes cumplieron.

Cuando al río de límpida corriente

Llegaron, y a Tos grandes lavaderos

De perenne agua clara, en que podría

Limpiarse cualquier cosa, aunque estuviese

De muy antiguo tiempo no lavada,

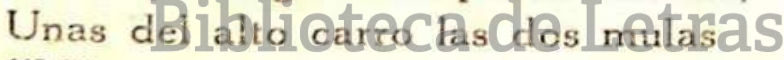

"Hija, yongeteniegra nil lasomulasso"

Desuncieron, y al río vorticoso

A pacer dulce grama las hecharon;

Otras del bello carro los vestidos

Tomando, y en el agua sumergiéndolos,

En celo compitiendo, pisoteáronlos

En las profundas pilas; y ya limpios

Tendiéronlos con orden en un vasto

Pedregal de la costa, cuyas piedras

A menudo la mar bañar solía.

Hecho esto, se lavaron y se ungieron;

$\mathrm{Y}$, mientras a los rayos del sol claro

$Y$ luciente, las ropas se secaban,

Hicieron su comida junto al río.

Cuando ya las doncellas y Nausicaa

Hubieron su apetito satisfecho,

Se quitaron los velos, y jugaron

Juntas a la pelota; la princesa

De níveo brazo, el juego dirigía.

Como en las agrias cumbres del Taigeto 
O el Erimanto, Diana cazadora,

El rey no sólo es rico por ël botín que le procuran sus expediciones militares sino por la posesión de ricos dominios. Sin embargo, no es el único poseedor de las tierras del clán; rodéanle otros propietarios, pequeños o grandes, que constituyen el grupo de ancianos de su pueblo. Por lo demás, tiene derecho al cobro de tributos regulares.

El rey es el magistrado supremo y universal; es a un mismo tiempo sacerdote, juez, administrador o jefe del ejército. Sin embargo no es un déspota absoluto, un príncipe oriental. Existe ya el germen del gobierno liberal en estas viejas monarquías, y lo recordaban así los griegos en edades posteriores. El rey homérico reune a los antiguos para juzgar; convoca a los grandes y en ocasiones al pueblo para asociarlos a sus resoluciones más importantes. Debe ser orador: Aquiles niño ha aprendido de Fénix las dos cosas que debe saber un rey, Obrar y hablar. En la epopeya puede entreverse lo que son estas asambleas. Cuando el rey apoyado en su bastón seleyanta y habla, una vez que el heraldo ha ordenado el silencio, se le escucha y casi nunca se le contradice; está rodeado de un gran respeto; si algún Tersitas se atreve a alzar la voz para combatirle con demasiada viveza, los ancianos y la multitud misma imponen silencio al contradictor impertinente, por medio de procedimientos expeditivos y rudos. No nos dejemos engañar, sin embargo; Tersitas tendrá su día; un pueblo que cree de tal modo en la virtud de la palabra y de la discusión está pronto a reconocer su fuerza aún en otros que no sean sus jefes hereditarios" (4). CaS

$$
\text { "Jorge Puecinelli-Gonverso" }
$$

Tal es la transparencia de los hechos históricos a través de los cantos heróices. Y si como lo cree Curtius, el cuadro trazado por el gran poeta y relativo al tiempo a que sus héroes pertenecen, no es fiel ni completo; en cambio su testimonio pasa más allá de ese tiempo; muestra la ruina del antiguo orden de cosas y la transición que preparó el nuevo. "Revela en verdad un mundo desconocido que se pierde en la lejanía del período preclásico, y en el cual se pone de manifiesto el valor de la raza que se formaba por el cruzamiento feliz de arios y semitas, y la revelación, a través de esa naciente cultura, de los vínculos sustanciales que había de asegurar su fuerza y su unidad.

Hoy, esos viejos cantares son para la historia una fuente de inapreciable valor inforrnativo; para los griegos fueron el libro santo de la nacionalidad, el Antiguo Testamento helénico, que mantuvo la fé en los altos destinos de ese pueblo privilegiado, y escogido también por la Providencia, para ser el creador de obras de belleza inefable.

\section{Horacio H. Urteaga.}

(1) Croiset. Las democracias griegas. 


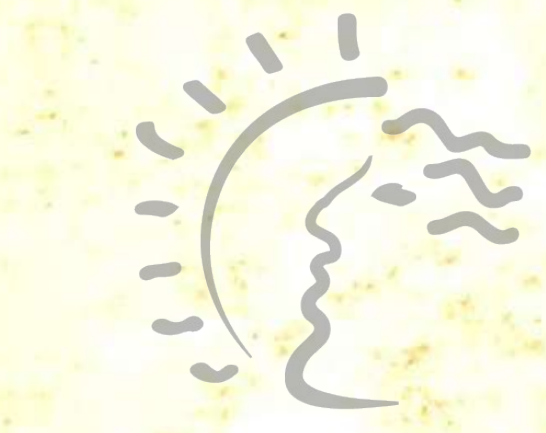

Biblioteca de Letras
"Jorge Puccinelli Converso" 